Supporting information

\title{
Cationic defect engineering for controlling the infrared absorption of hexagonal cesium
} tungsten bronze nanoparticles

Shuhei Nakakura ${ }^{1,2}$, Aditya Farhan Arif ${ }^{1}$, Keisuke Machida ${ }^{2}$, Kenji Adachi ${ }^{2}$ and Takashi $\mathrm{Ogi}^{1 *}$

${ }^{1}$ Department of Chemical Engineering, Hiroshima University, 1-4-1 Kagamiyama, Higashi Hiroshima, Hiroshima 739-8527, Japan.

${ }^{2}$ Ichikawa Research Center, Sumitomo Metal Mining Co., Ltd, 3-18-5, Nakakokubun, Ichikawa, Chiba 272-8588, Japan.

Table of content

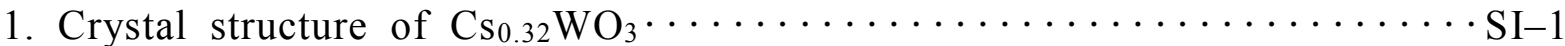

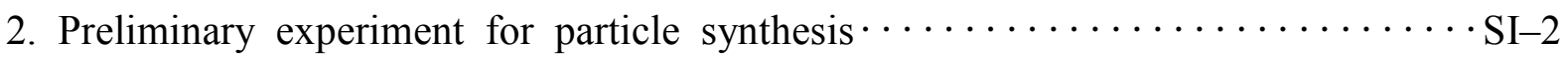

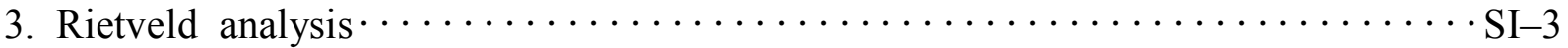

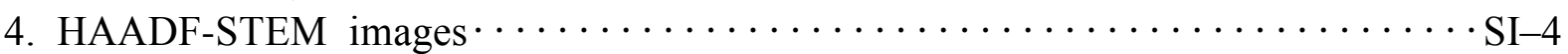

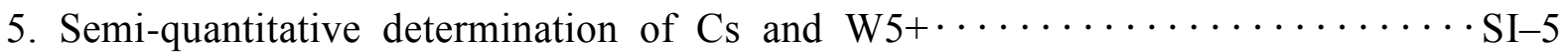

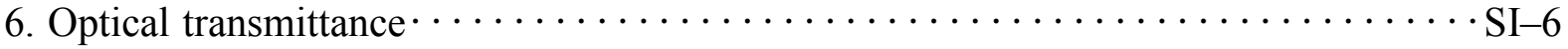




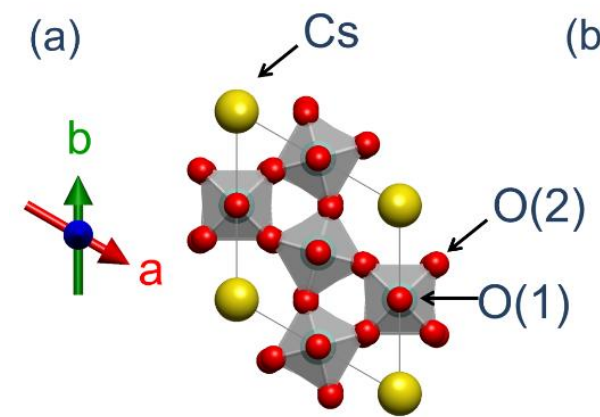

(b)

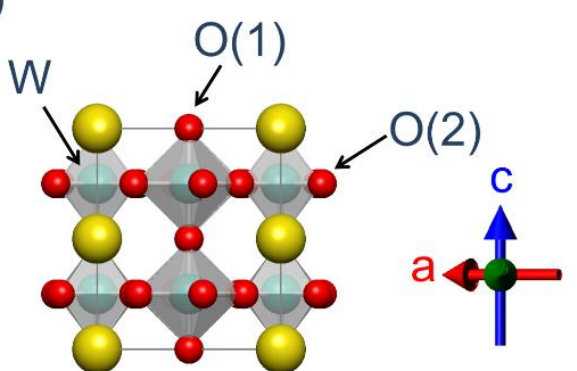

Figure S1 (a)c-axis, (b) b-axis projections of $\mathrm{Cs}_{0.32} \mathrm{WO}_{3}$ crystal (ICDD No.04-009-6455)

The space group of $\mathrm{Cs}_{0.32} \mathrm{WO}_{3}$ crystal is $P 6_{3} / \mathrm{mcm}$. $\mathrm{WO}_{6}$ octahedra consist of hexagonal structure where Cs atoms are positioned in the center of the hexagonal cavities as shown in Figure S1(a). The crystal structure of $\mathrm{Cs}_{0.32} \mathrm{WO}_{3}$ is composed from the c planes including $\mathrm{Cs}$ atoms and W atoms alternatingly as shown in Figure S1(b). Oxygen atoms contained in c planes including Cs atoms and $\mathrm{W}$ atoms are called $\mathrm{O}(1)$ and $\mathrm{O}(2)$, respectively.

\section{SI-2. Preliminary experiment for particle synthesis}

A set of preliminary experiments was performed for the synthesis of initial $\mathrm{Cs}_{0.32} \mathrm{WO}_{3}$ particles using spray pyrolysis. In spray pyrolysis, the temperatures in the earlier zones of the furnace are designed to promote self-assembly of the precursor in the droplets and solvent evaporation. The critical zone where the precursor is converted into a particle is usually at the end of the furnace. Specifically, in the production of metals and metal oxides, the temperature of the end zone of the furnace determines the crystal structure of the final particle. On the basis of this background, the temperature of the last two zones of the furnace in this research was varied to evaluate its effect on the crystal structure. The temperature of these zones was then referred to as the synthesis temperature.

Figure S2 shows the XRD spectrum of the particles prepared at synthesis temperatures of 1000, 1100, 1200, 1300, and $1400^{\circ} \mathrm{C}$. As shown in Figures S2(a) and (b), the spectra of the particles prepared at 1000 and $1100{ }^{\circ} \mathrm{C}$ were identical and corresponded with the peaks of $\mathrm{Cs}_{0.32} \mathrm{WO}_{3}$ (ICDD file No.04-009-6455) and $\left(\mathrm{Cs}_{2} \mathrm{O}\right)_{0.44} \mathrm{~W}_{2} \mathrm{O}_{6}$ (ICDD No.00-47-0566), which indicated a successful synthesis of $\mathrm{Cs}_{0.32} \mathrm{WO}_{3}$ using spray pyrolysis. New peaks corresponding to those of $\left(\mathrm{H}_{2} \mathrm{O}\right)_{0.33} \mathrm{WO}_{3}$ (ICDD No.01-072-0199) and $\mathrm{WO}_{2}$ (ICDD No.00-32-1393) appeared when the synthesis temperature was $1200{ }^{\circ} \mathrm{C}$, but $\mathrm{Cs}_{0.32} \mathrm{WO}_{3}$ remained as the main phase, as depicted in Figure S2(c). The $\left(\mathrm{Cs}_{2} \mathrm{O}\right)_{0.44} \mathrm{~W}_{2} \mathrm{O}_{6}$ phase is shown 
to increase progressively when the synthesis temperature was increased up to $1400{ }^{\circ} \mathrm{C}$ due apparently to the shorter crystallization time at elevated temperatures (Figure S2(d, e)).

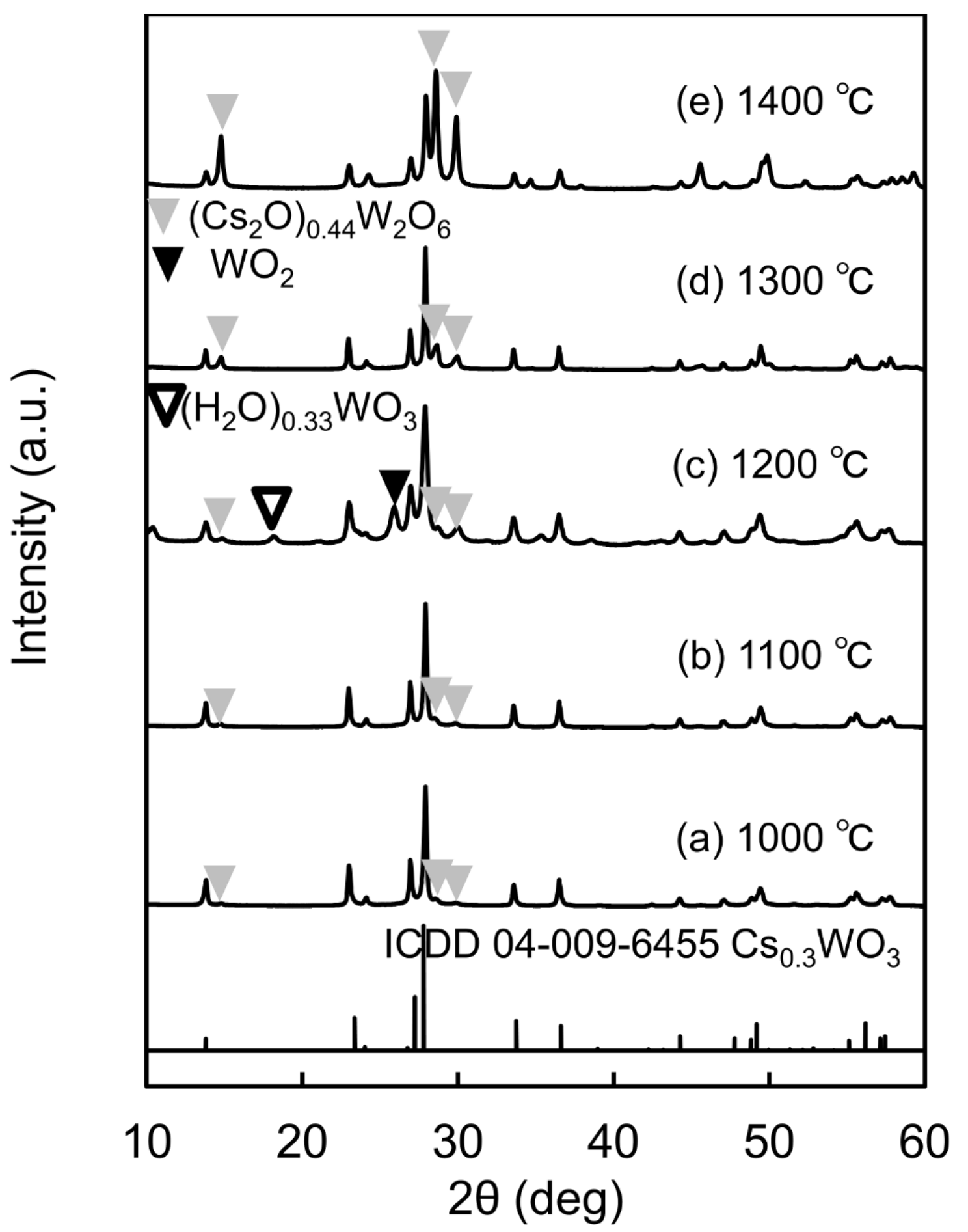

Figure S2. Effect of synthesis temperature on the crystal structure of particles prepared by spray pyrolysis. 
Besides the resulting crystal structure, the synthesis temperature also affected the particle size and morphology. As shown in Figures S3(a) and (b), a mixture of coarse hexagonal particles of 100-300 $\mathrm{nm}$ in size and fine particles of $\sim 20 \mathrm{~nm}$ were formed when the synthesis temperature was 1000 and $1100{ }^{\circ} \mathrm{C}$; that is, when the structure of the particle consisted only of $\mathrm{Cs}_{0.32} \mathrm{WO}_{3}$. However, the particle size tended to be smaller when the synthesis temperature was $1100{ }^{\circ} \mathrm{C}$ because of the surface segregation, which formed smaller particles, as seen in Figure S3(c). Applying a synthesis temperature of $1300{ }^{\circ} \mathrm{C}$ produced cubic-shaped particles, as shown in Figure S3(d). The synthesis condition appeared to be favorable for the formation of $\left(\mathrm{Cs}_{2} \mathrm{O}\right)_{0.44} \mathrm{~W}_{2} \mathrm{O}_{6}$ phase, which was indicated by the continuous growth of the $\left(\mathrm{Cs}_{2} \mathrm{O}\right)_{0.44} \mathrm{~W}_{2} \mathrm{O}_{6}$ that increased the particle size to $60 \mathrm{~nm}$. The particle was enlarged further to $\sim 75 \mathrm{~nm}$ when the synthesis temperature was set at $1400{ }^{\circ} \mathrm{C}$ (Figure S3(e)). The average particle size decreased further to $\sim 50 \mathrm{~nm}$ when the synthesis temperature was $1200{ }^{\circ} \mathrm{C}$ as many large particles became segregated into nanoparticles, as shown in Figure S3(f). This phenomenon, illustrated in Figure S3(g), occurred at the high temperature zones (zones 4 and 5) of the furnace. 

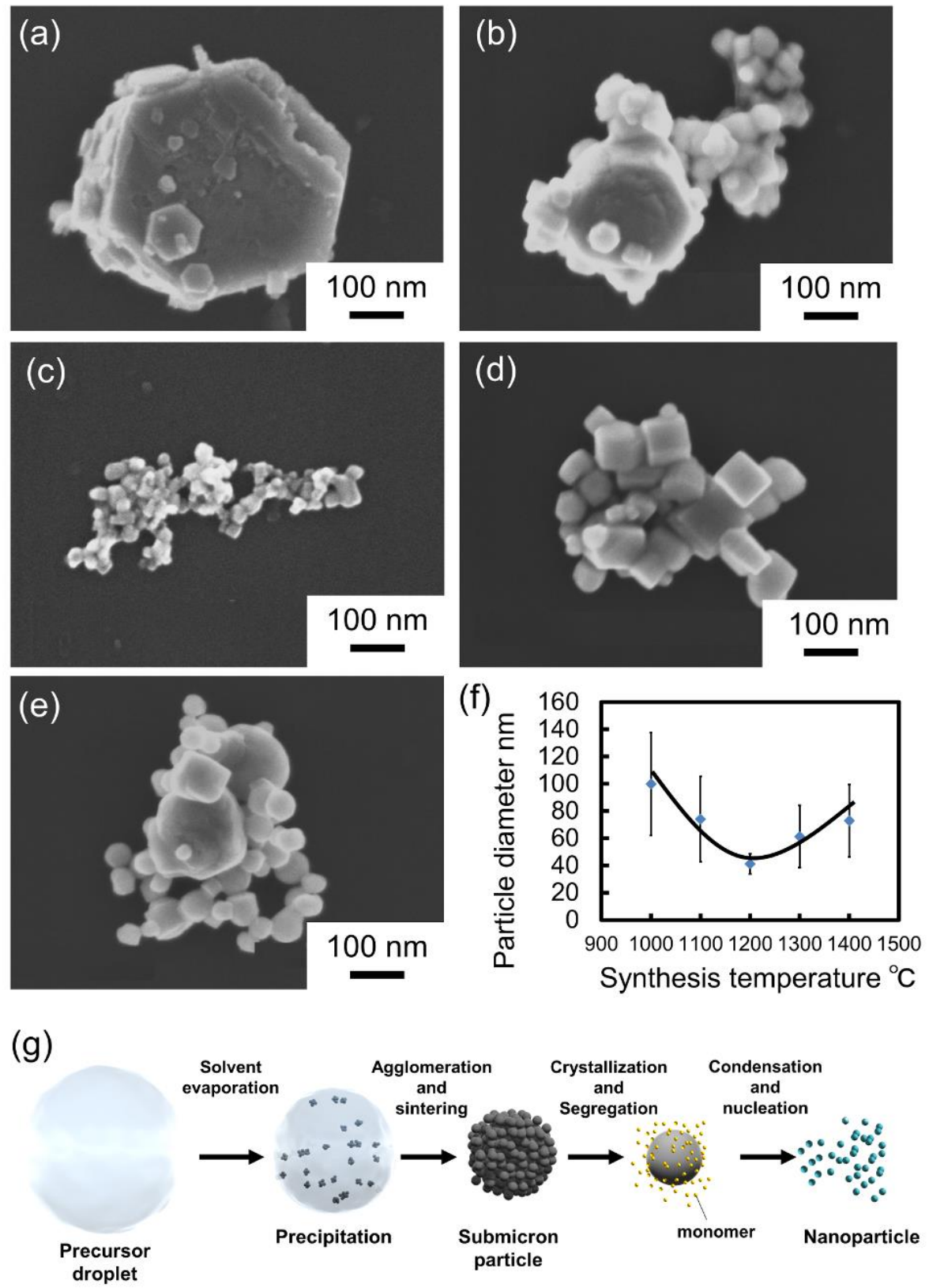

Figure S3. SEM images of particles prepared at (a) $1000^{\circ} \mathrm{C}$, (b) $1100{ }^{\circ} \mathrm{C}$, (c) $1200{ }^{\circ} \mathrm{C}$, (d) $1300{ }^{\circ} \mathrm{C}$, and (e) $1400{ }^{\circ} \mathrm{C}$, (f) the temperature dependence of particle diameter, and (g) particle formation mechanism through spray pyrolysis. 


\section{SI-3. Rietveld analysis}

\section{SI-3.1. The Rietveld refinements of samples before and after heat treatment}

We conducted the Rietveld refinements for crystal phases of $\mathrm{Cs}_{0.32} \mathrm{WO}_{3}$ (ICDD No.04-009-6455), $\left(\mathrm{Cs}_{2} \mathrm{O}\right)_{0.44} \mathrm{~W}_{2} \mathrm{O}_{6}$ (ICDD No.00-47-0566), $\mathrm{W}_{11} \mathrm{O}_{22}$ (ICDD No.04-007-0719), $\left(\mathrm{H}_{2} \mathrm{O}\right)_{0.33} \mathrm{WO}_{3}$ (ICDD No.01-072-0199), ATP (ICDD No.00-040-1470), and $\mathrm{WO}_{2}$ (ICDD No.00-032-1393). The space group of $\mathrm{Cs}_{0.32} \mathrm{WO}_{3}$ phase assumed $P 6_{3} / \mathrm{mcm}$. The atomic coordinates of $x$ in $\mathrm{W}-6 \mathrm{~g}, x$ in $\mathrm{O}(1)-12 \mathrm{k}$ and $x$ and $y$ in $\mathrm{O}(2)-12 \mathrm{j}$ were optimized. The coordinate of $\mathrm{Cs}-2 \mathrm{~b}$ was fixed at $(0,0,0)$. The site occupancies $\left(S_{\mathrm{Cs}}, S_{\mathrm{W}}, S_{\mathrm{O}(1)}\right.$, and $\left.S_{\mathrm{O}(2)}\right)$ of $\mathrm{Cs}, \mathrm{W}, \mathrm{O}(1)$, and $\mathrm{O}(2)$ were treated as a parameter of Rietveld refinements. The $S_{\mathrm{O}(1)}$ and $S_{\mathrm{O}(2)}$ were restricted as less than 0.5 and 1 , respectively. The temperature factors $\left(B_{\mathrm{Cs}}, B_{\mathrm{W}}, B_{\mathrm{O}(1)}\right.$, and $\left.B_{\mathrm{O}(2)}\right)$ were fixed literature values $\left(0.86,1.14,0.59\right.$, and 0.28 , respectively) in $\mathrm{Cs}_{0.32} \mathrm{WO}_{3}$ (ICDD No.04-009-6455). The conformity between calculation and observed patterns was evaluated by the indexes of $R$-weighted pattern $\left(R_{\mathrm{wp}}\right), R$-expected $\left(R_{\exp }\right)$ and goodness of fit $\left(G O F=R_{\mathrm{wp}} / R_{\exp }\right)^{23}$. The results of Rietveld refinements are shown in Table S1. In these refinements, $R_{\exp }$ values were small as indicated in the range of 1.44 to 1.57 due to the strong $\mathrm{X}$-ray diffraction intensity, leading to the values of GOF in between 3.9 and 5.65. 
Table S1. $\boldsymbol{R}$ factor, Mass fraction, Lattice parameter, and Atomic coordinate from Rietveld analysis. Numbers in parentheses are uncertainties in the last digit.

\begin{tabular}{|c|c|c|c|c|c|c|}
\hline & & & $\begin{array}{c}\text { Before heat } \\
\text { treatment } \\
\text { (As-synthesized) }\end{array}$ & $\begin{array}{c}\text { After heat } \\
\text { treatment at } \\
3^{300}{ }^{\circ} \mathrm{C}\end{array}$ & $\begin{array}{c}\text { After heat } \\
\text { treatment at } \\
\quad 450{ }^{\circ} \mathrm{C}\end{array}$ & $\begin{array}{c}\text { After heat } \\
\text { treatment at } \\
650^{\circ} \mathrm{C}\end{array}$ \\
\hline \multirow{3}{*}{$R$ factor } & \multicolumn{2}{|c|}{$R_{\mathrm{wp}}$} & 8.13 & 5.94 & 6.56 & 8.91 \\
\hline & \multicolumn{2}{|c|}{$R_{\exp }$} & 1.44 & 1.52 & 1.52 & 1.57 \\
\hline & \multicolumn{2}{|c|}{ GOF } & 5.65 & 3.9 & 4.32 & 5.64 \\
\hline \multirow{6}{*}{$\begin{array}{c}\text { Mass fraction } \\
(\%)\end{array}$} & \multirow{2}{*}{\multicolumn{2}{|c|}{$\begin{array}{c}\mathrm{Cs}_{0.32} \mathrm{WO}_{3} \\
\left(\mathrm{Cs}_{2} \mathrm{O}\right)_{0.44} \mathrm{~W}_{2} \mathrm{O}_{6}\end{array}$}} & $52(4)$ & $65(5)$ & $72(6)$ & $85(7)$ \\
\hline & & & $21(5)$ & $12(3)$ & $7(3)$ & $5(6)$ \\
\hline & \multicolumn{2}{|c|}{$\mathrm{W}_{11} \mathrm{O}_{22}$} & $9(5)$ & $7(5)$ & $6(7)$ & $4(2)$ \\
\hline & \multicolumn{2}{|c|}{$\left(\mathrm{H}_{2} \mathrm{O}\right)_{0.33} \mathrm{WO}_{3}$} & $5.5(7)$ & $3.9(4)$ & $4.7(5)$ & $2.4(3)$ \\
\hline & \multicolumn{2}{|c|}{ ATP } & $6.0(10)$ & $6.9(8)$ & $4.2(7)$ & $2.2(7)$ \\
\hline & \multicolumn{2}{|c|}{$\mathrm{WO}_{2}$} & $5(2)$ & $4.6(19)$ & $4(2)$ & $0(2)$ \\
\hline \multirow{2}{*}{$\begin{array}{c}\text { Lattice } \\
\text { parameter }\end{array}$} & \multicolumn{2}{|c|}{ a $(\AA)$} & $7.3756(5)$ & $7.3742(4)$ & $7.3871(4)$ & $7.4180(4)$ \\
\hline & \multicolumn{2}{|c|}{$c(\AA)$} & $7.7147(8)$ & $7.7038(6)$ & $7.6737(6)$ & $7.5885(5)$ \\
\hline \multirow{9}{*}{$\begin{array}{c}\text { Atomic } \\
\text { coordinate }\end{array}$} & \multirow{3}{*}{ W-6g } & $x$ & $0.4945(16)$ & $0.4948(11)$ & $0.4921(7)$ & $0.4827(2)$ \\
\hline & & $y$ & 0 & 0 & 0 & 0 \\
\hline & & $z$ & $1 / 4$ & $1 / 4$ & $1 / 4$ & $1 / 4$ \\
\hline & \multirow{3}{*}{$\begin{array}{c}\mathrm{O}(1)- \\
12 \mathrm{k}\end{array}$} & $x$ & $0.524(10)$ & $0.518(10)$ & $0.523(8)$ & $0.528(8)$ \\
\hline & & $y$ & 0 & 0 & 0 & 0 \\
\hline & & $z$ & 0.01 & 0.01 & 0.01 & 0.01 \\
\hline & \multirow{3}{*}{$\mathrm{O}(2)-12 \mathrm{j}$} & $x$ & $0.177(4)$ & $0.195(5)$ & $0.198(4)$ & $0.212(2)$ \\
\hline & & $y$ & $0.4135(18)$ & $0.4145(12)$ & $0.4102(12)$ & $0.4178(16)$ \\
\hline & & $z$ & $1 / 4$ & $1 / 4$ & $1 / 4$ & $1 / 4$ \\
\hline \multirow{4}{*}{$\begin{array}{c}\text { Site } \\
\text { occupancy }\end{array}$} & \multicolumn{2}{|l|}{$S_{\mathrm{Cs}}$} & $0.607(6)$ & $0.619(3)$ & $0.635(3)$ & $0.779(4)$ \\
\hline & \multicolumn{2}{|l|}{$S_{\mathrm{W}}$} & $0.786(3)$ & $0.8444(17)$ & $0.8737(18)$ & $1.0000(12)$ \\
\hline & \multicolumn{2}{|c|}{$S_{\mathrm{O}(1)}$} & $0.358(17)$ & $0.348(11)$ & $0.370(12)$ & $0.380(11)$ \\
\hline & \multicolumn{2}{|c|}{$S_{\mathrm{O}(2)}$} & $1.00(2)$ & $1.000(14)$ & $1.000(14)$ & $0.935(14)$ \\
\hline
\end{tabular}




\section{SI-3.2. The Rietveld refinements of samples at different synthesis temperatures}

We conducted the Rietveld refinements for the crystalline phases of $\mathrm{Cs}_{0.32} \mathrm{WO}_{3}$ (ICDD No.04-009-6455) and $\left(\mathrm{Cs}_{2} \mathrm{O}\right)_{0.44} \mathrm{~W}_{2} \mathrm{O}_{6}$ (ICDD No.00-47-0566) for the analysis. The space group of $\mathrm{Cs}_{0.32} \mathrm{WO}_{3}$ phase was assumed $P 6_{3} / \mathrm{mcm}$. The atomic coordinates of $x$ in $\mathrm{W}-6 \mathrm{~g}$ site, $x$ in $\mathrm{O}(1)-12 \mathrm{k}$, and $x$ and $y$ in $\mathrm{O}(2)-12 \mathrm{j}$ were optimized. The coordinates of Cs-2b was fixed at $(0,0,0)$. The site occupancies $\left(S_{\mathrm{Cs}}, S_{\mathrm{W}}, S_{\mathrm{O}(1)}\right.$, and $\left.S_{\mathrm{O}(2)}\right)$ of Cs, W, $\mathrm{O}(1)$ and $\mathrm{O}(2)$ were treated as parameters in the Rietveld analysis. The $S_{\mathrm{O}(1)}$, and $S_{\mathrm{O}(2)}$ were constrained to be less than 0.5 and 1 , respectively. The temperature factors $\left(B_{\mathrm{Cs}}\right.$, $B_{\mathrm{W}}, B_{\mathrm{O}(1)}$, and $\left.B_{\mathrm{O}(2)}\right)$ were fixed literature values $(0.86,1.14,0.59$, and 0.28 , respectively) in $\mathrm{Cs}_{0.32} \mathrm{WO}_{3}$ (ICDD No.04-009-6455). The agreement between calculated and observed patterns was evaluated from three parameters, namely $R_{\mathrm{wp}}, R_{\mathrm{exp}}$, and $G O F .^{23}$ The results of the Rietveld analysis are shown in Table S2. In these refinements, $R_{\exp }$ values were small as indicated in the range of 1.33 to 1.43 due to the strong X-ray diffraction intensity, leading to the values of GOF in between 5.95 and 7.18. 
Table S2. $\boldsymbol{R}$ factor, Mass fraction, Lattice parameter, and Atomic coordinate from Rietveld analysis. Numbers in parentheses are uncertainties in the last digit.

\begin{tabular}{|c|c|c|c|c|c|c|}
\hline & & & $\begin{array}{c}\text { Synthesis } \\
\text { temperature at } \\
1000{ }^{\circ} \mathrm{C}\end{array}$ & $\begin{array}{c}\text { Synthesis } \\
\text { temperature at } \\
1100{ }^{\circ} \mathrm{C}\end{array}$ & $\begin{array}{c}\text { Synthesis } \\
\text { temperature at } \\
1300{ }^{\circ} \mathrm{C}\end{array}$ & $\begin{array}{c}\text { Synthesis } \\
\text { temperature at } \\
1400{ }^{\circ} \mathrm{C}\end{array}$ \\
\hline \multirow{3}{*}{$R$ factor } & \multicolumn{2}{|c|}{$R_{\text {wp }}$} & 9.55 & 7.94 & 8.96 & 8.79 \\
\hline & \multicolumn{2}{|c|}{$R_{\exp }$} & 1.33 & 1.34 & 1.43 & 1.42 \\
\hline & \multicolumn{2}{|c|}{$G O F$} & 7.18 & 5.95 & 6.27 & 6.19 \\
\hline \multirow{2}{*}{ Mass fraction } & \multirow{2}{*}{\multicolumn{2}{|c|}{$\begin{array}{c}\mathrm{Cs}_{0.32} \mathrm{WO}_{3}(\%) \\
\left(\mathrm{Cs}_{2} \mathrm{O}\right)_{0.44} \mathrm{~W}_{2} \mathrm{O}_{6} \\
(\%)\end{array}$}} & $95.98(18)$ & $94.67(15)$ & $80.03(18)$ & $42.3(2)$ \\
\hline & & & $4.02(18)$ & $5.33(15)$ & $19.97(18)$ & $57.7(2)$ \\
\hline \multirow{2}{*}{$\begin{array}{c}\text { Lattice } \\
\text { parameter }\end{array}$} & \multicolumn{2}{|c|}{$\mathrm{a}(\AA)$} & $7.3703(3)$ & $7.3660(2)$ & $7.3619(2)$ & $7.3548(4)$ \\
\hline & \multicolumn{2}{|c|}{ c $(\AA)$} & $7.7083(3)$ & $7.7124(3)$ & $7.7141(3)$ & $7.7074(6)$ \\
\hline \multirow{9}{*}{$\begin{array}{l}\text { Atomic } \\
\text { coordinate }\end{array}$} & \multirow{3}{*}{$\mathrm{W}-6 \mathrm{~g}$} & $x$ & $0.4904(4)$ & $0.4947(4)$ & $0.4965(7)$ & $0.4936(13)$ \\
\hline & & $y$ & 0 & 0 & 0 & 0 \\
\hline & & $z$ & $1 / 4$ & $1 / 4$ & $1 / 4$ & $1 / 4$ \\
\hline & \multirow{2}{*}{$\mathrm{O}(1)-$} & $x$ & $0.539(4)$ & $0.539(4)$ & $0.534(5)$ & $0.52(2)$ \\
\hline & & $y$ & 0 & 0 & 0 & 0 \\
\hline & $12 \mathrm{k}$ & $z$ & 0.01 & 0.01 & 0.01 & 0.01 \\
\hline & \multirow{3}{*}{$\mathrm{O}(2)-12 \mathrm{j}$} & $x$ & $0.2428(19)$ & $0.2478(15)$ & $0.234(3)$ & $0.231(8)$ \\
\hline & & $y$ & $0.4256(9)$ & $0.4252(8)$ & $0.4206(10)$ & $0.429(2)$ \\
\hline & & $z$ & $1 / 4$ & $1 / 4$ & $1 / 4$ & $1 / 4$ \\
\hline \multirow{4}{*}{$\begin{array}{c}\text { Site } \\
\text { occupancy }\end{array}$} & \multicolumn{2}{|c|}{$S_{\mathrm{Cs}}$} & $0.483(3)$ & $0.485(2)$ & $0.546(3)$ & $0.700(7)$ \\
\hline & \multicolumn{2}{|c|}{$S_{\mathrm{W}}$} & $0.7034(10)$ & $0.6798(8)$ & $0.7148(10)$ & $0.964(2)$ \\
\hline & \multicolumn{2}{|c|}{$S_{\mathrm{O}(1)}$} & $0.283(10)$ & $0.267(8)$ & $0.288(11)$ & $0.34(2)$ \\
\hline & \multicolumn{2}{|c|}{$S_{\mathrm{O}(2)}$} & $1.000(15)$ & $1.000(12)$ & $1.000(17)$ & $1.00(4)$ \\
\hline
\end{tabular}




\section{SI-3.3. Refinement parameters}

Definitions of refinement parameters in TOPAS by Young ${ }^{23,24}$ are shown in Table S3. $Y_{o, m}$ and $Y_{c, m}$ are given by the observed and calculated intensity values at data point $m . \mathrm{M}$ and $\mathrm{P}$ are the number of data points and parameters, respectively. $w_{m}$ is the weight at data point $m$ and it is given by $w_{\mathrm{m}}=1 / \sigma\left(Y_{o, m}\right)^{2}$, where $\sigma\left(Y_{o, m}\right)$ is the error in $Y_{o, m}$.

Table S3. Definitions of $R$-weighted pattern $\left(R_{\mathrm{wp}}\right), R$-expected $\left(R_{\exp }\right)$, and goodness of fit (GOF)

\begin{tabular}{cc}
\hline \hline$R$-weighted pattern $\left(R_{\mathrm{wp}}\right)$ & Definition \\
\hline$R$-expected $\left(R_{\mathrm{exp}}\right)$ & $R_{\mathrm{wp}}=\sqrt{\frac{\sum w_{m}\left(Y_{o, m}-Y_{c, m}\right)^{2}}{\sum w_{m} Y_{o, m}^{2}}}$ \\
\hline goodness of fit $(G O F)$ & $R_{\exp }=\sqrt{\frac{M-P}{\sum w_{m} Y_{o, m}^{2}}}$ \\
\hline \hline
\end{tabular}

\section{SI-4. HAADF-STEM images}
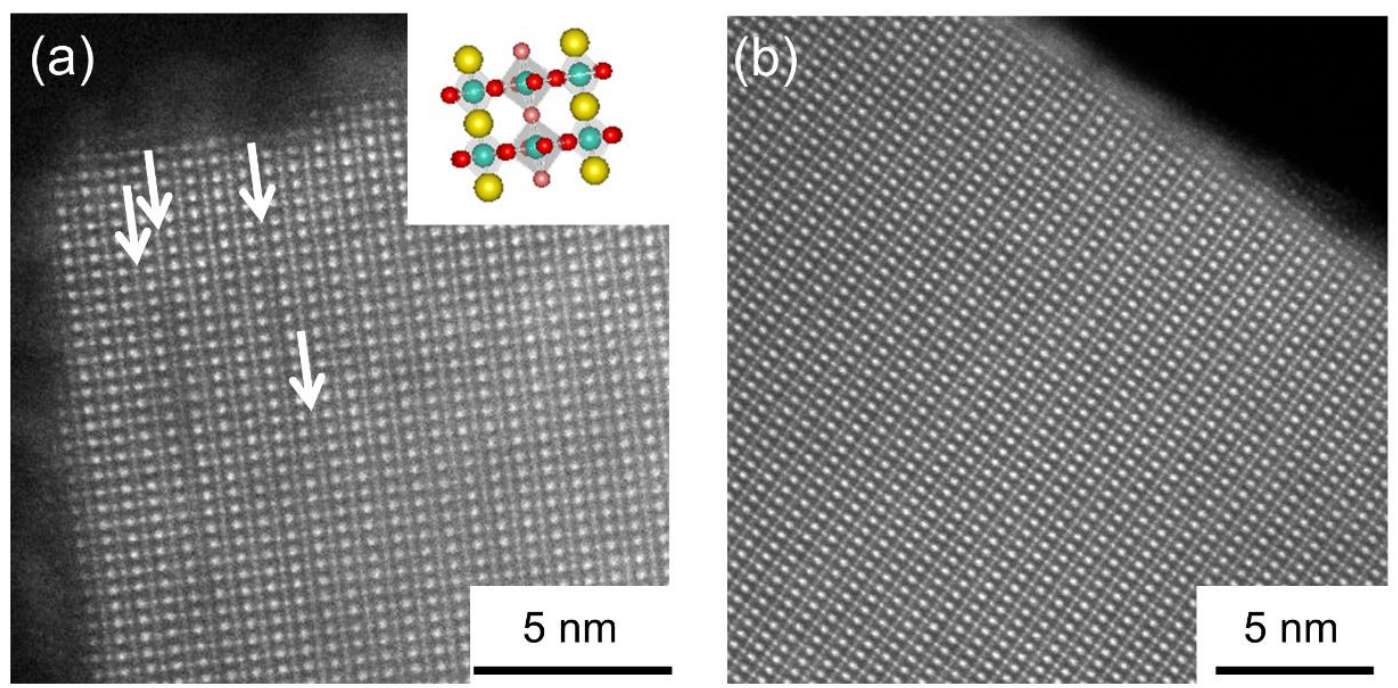

Figure S4. HAADF-STEM images of the samples (a) before and (b) after heat treatment at $650{ }^{\circ} \mathrm{C}$ in $5 \% \mathrm{H}_{2} / \mathrm{Ar}$ atmosphere. Inset of (a) illustrates the atomic arrangement of the structure from the [010] direction. 


\section{SI-5. Semi-quantitative determination of $\mathrm{Cs}$ and $\mathrm{W}^{\mathbf{5}}$}

XPS semi-quantitative determination of $\mathrm{Cs} / \mathrm{W}$ and $\mathrm{W}^{5+} / \mathrm{W}$ (atomic ratio) are shown in

Table S3. These values were estimated from the area ratio of W $4 f$ and Cs $3 d$ spectra with relative sensitive factors (RSFs). The RSFs of Cs $(=38.73)$ and $\mathrm{W}(=10.27)$ installed in the XPS apparatus (ESCA-3400) were used.

Table S3. Cs/W and $\mathrm{W}^{5+} / \mathrm{W}$ from XPS measurements

\begin{tabular}{ccc}
\hline \hline & $\begin{array}{c}\mathbf{C s} / \mathbf{W} \\
\text { (atomic ratio) }\end{array}$ & $\begin{array}{c}\text { W5+/W } \\
\text { (atomic ratio) }\end{array}$ \\
\hline As synthesized & 0.114 & 0.0 \\
After heat treatment at $650{ }^{\circ} \mathrm{C}$ & 0.191 & 0.269 \\
\hline \hline
\end{tabular}

\section{SI-6. Optical transmittance}

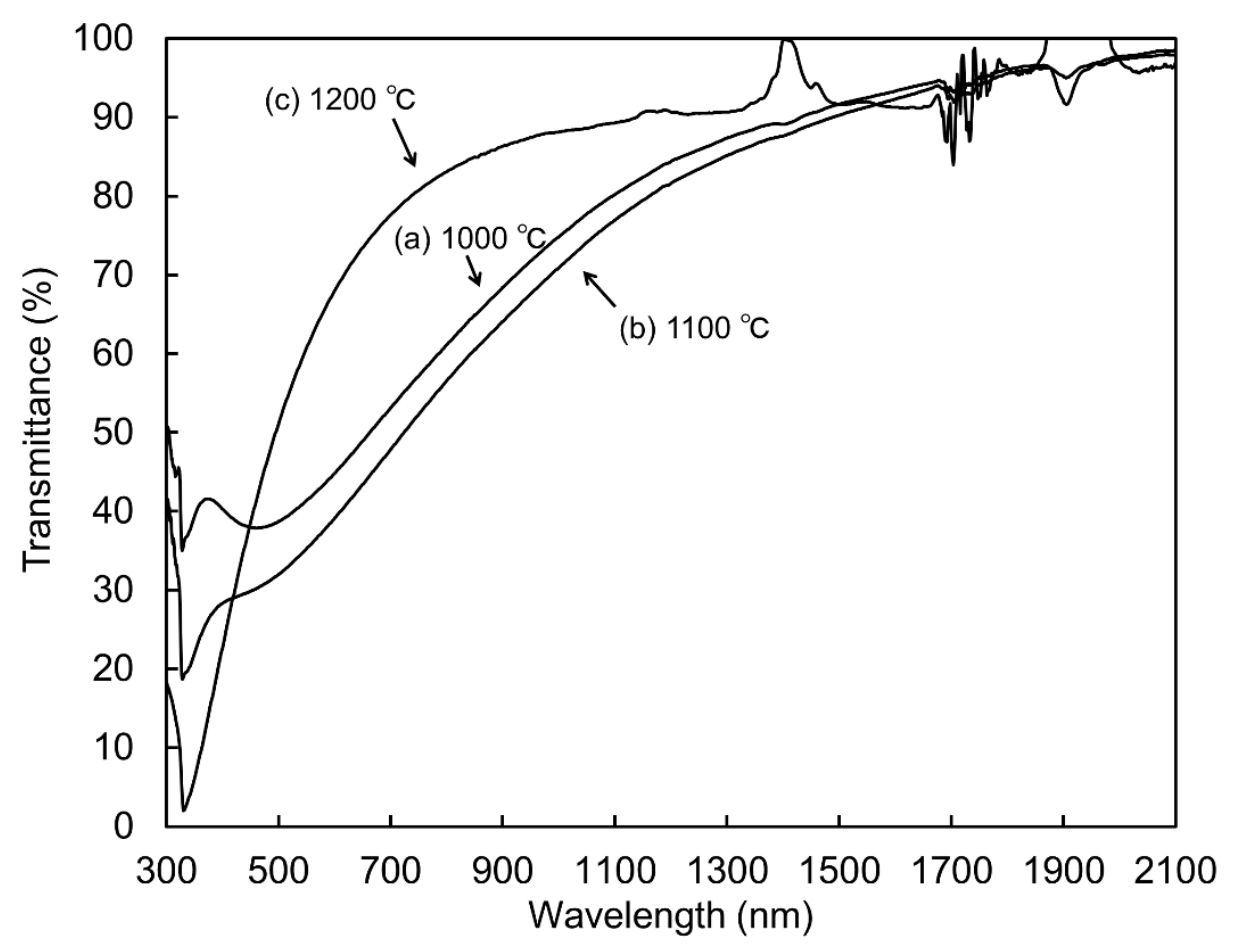

Figure S5. Optical transmittance of the as-synthesized samples of synthesis temperatures of (a) 1000 , (b) 1100 , and (c) $1200{ }^{\circ} \mathrm{C}$. 